\title{
Discrepancies between Clinical and Autopsy Diagnoses in the Emergency Department of the University Hospital of the West Indies
}

\author{
TN Gibson ${ }^{1}$, SE Shirley ${ }^{1}$, EW Williams ${ }^{2}$, A Rhudd ${ }^{2}$, S French ${ }^{2}$, R Hibbert ${ }^{2}$
}

\begin{abstract}
Objectives: To determine the cause of death diagnoses and the discrepancy rate between clinical and autopsy diagnoses in the Emergency Department (ED) of the University Hospital of the West Indies (UHWI).

Methods: Clinical and post-mortem records were reviewed for all the patients dying in the ED of the UHWI within 24 hours of their admission, during the period January 2007 to December 2010. The patients'demographic data, clinical cause of death and cause of death established at autopsy were documented for each case. The clinical diagnoses were classified as being either concordant (similar) or discrepant (dissimilar) with respect to the pathologic diagnosis, using a modified Underwood classification. The frequencies of diagnostic discrepancy were analysed with respect to disease category, gender and age.

Results: For the study period, 68 of the 180 patients who died in the ED within 24 hours of their admission received autopsies (autopsy rate, 37.8\%), and they ranged in age from 11-92 years (mean 54.9); M: F ratio, 1.4:1. The commonest autopsy cause of death category was circulatory disorders; cardiovascular diseases were more common than cerebrovascular diseases. The discrepancy rate between the clinical and autopsy cause of death diagnoses was $36.8 \%$. The frequency of discrepancies increased with age; the majority (57.9\%) occurred in patients $\geq 50$ years of age.

Conclusions: The autopsy rate, distribution of cause of death diagnoses and discrepancy rate documented in our ED are comparable to similar studies. The high frequency of discrepant diagnoses among older age groups, combined with the diagnostic challenges in the ED related to time and patient co-morbidities, warrant a concerted effort to increase the autopsy rate.
\end{abstract}

Keywords: Autopsy, cause of death, diagnostic errors, emergency service, hospital standards

\section{Discrepancias entre los Diagnósticos Clínicos y los Diagnósticos por Autopsia en el Departamento de Emergencias del Hospital Universitario de West Indies}

\author{
TN Gibson ${ }^{1}$, SE Shirley ${ }^{1}$, EW Williams ${ }^{2}$, A Rhudd ${ }^{2}$, S French ${ }^{2}$, R Hibbert ${ }^{2}$
}

\begin{abstract}
RESUMEN
Objetivos: Determinar las causas en diagnósticos de muerte, y la tasa de discrepancia entre los diagnósticos clínicos y por autopsia en el Departamento de Emergencias (DE) del Hospital Universitario de West Indies (HUWI).

Métodos: Se revisaron las historias clínicas y post mortem de todos los pacientes que murieron en el DE del UHWI dentro de las 24 horas de su ingreso, durante el periodo de enero de 2007 a diciembre de 2010. Los datos demográficos de los pacientes, las causas clínicas de muerte y
\end{abstract}

From: ${ }^{1}$ Department of Pathology and ${ }^{2}$ Emergency Medicine Division, Department of Surgery, Radiology, Anaesthesia and Intensive Care, The University of the West Indies, Kingston 7, Jamaica West Indies.
Correspondence: Dr TN Gibson, Department of Pathology, The University of the West Indies, Kingston 7, Jamaica, West Indies. Email: tracey.gibson@ uwimona.edu.jm 
las causas de muerte establecidas en la autopsia, fueron documentados en cada caso. Los diagnósticos clínicos fueron clasificados como concordantes (similares), o discrepantes (disímiles) con respecto a la diagnosis patológica, usando una clasificación modificada de Underwood. Se analizaron las frecuencias de las discrepancias de diagnósticos con respecto a edad, género y categoría de enfermedad.

Resultados: En el período de estudio, 68 de los 180 pacientes que murieron en el DE dentro de las 24 horas de su ingreso recibieron autopsias (tasa de autopsia, 37.8\%), y su rango de edad fue de 11 - 92 años (54.9); relación V:H, 1.4:1. La categoría más común de causa de muerte en las autopsias fueron los trastornos circulatorios. Las enfermedades cardio-vasculares fueron más frecuentes que las enfermedades cerebrovasculares. La tasa de discrepancia entre el diagnóstico clínico y el de autopsia con respecto a las causas de las muertes fue de 36.8\%. La frecuencia de discrepancias aumentó con la edad. La mayor parte (57.9\%) de las muertes ocurrieron en pacientes de $>50$ años.

Conclusiones: La tasa de autopsia, la distribución de diagnósticos de causa de muerte, y la tasa de discrepancia documentada en nuestro DE son comparables a estudios similares. La alta frecuencia de diagnósticos discrepantes entre los grupos de mayor edad, combinada con los desafios del diagnóstico en el DE relacionados con el tiempo y las comorbilidades del paciente, garantizan que se haga un esfuerzo concertado para aumentar la tasa de la autopsia.

Palabras claves: Autopsia, causa de muerte, errores de diagnóstico, servicio de emergencia, hospital y normas

West Indian Med J 2017; 66 (2): 312

\section{INTRODUCTION}

The Emergency Department (ED) is the first point of physician-patient contact in the tertiary care setting. It facilitates a wide cross-section of the population with varying pathologies and severities. As such, the efficient functioning of an ED with regards to triaging, diagnosing and treatment can play a significant role in the overall quality of patients' care. One indicator of clinical diagnostic accuracy, and consequent contributor to patients' outcomes, is the rate of discrepancy between clinical and autopsy diagnoses. It has been consistently shown that this rate has remained relatively high worldwide, despite improvements in clinical diagnostic technologies (1-4).

We previously documented an overall discrepancy rate of $48.4 \%$ between clinical and autopsy diagnoses at the University Hospital of the West Indies (UHWI); the analyses by clinical service revealed a discrepancy rate of $66.4 \%$, for major and minor diagnoses combined, for the ED (5). Whereas our previous investigation analysed all documented clinical and post-mortem diagnoses, the current study focusses specifically on cause of death diagnoses in patients dying in the ED within 24 hours of their admission, in an attempt to identify the specific diagnostic challenges which may contribute to mortality in our ED. This is the first such study from the English-speaking Caribbean.

\section{SUBJECTS AND METHODS}

For the period January 2007 to December 2010, records were retrieved for all the patients dying in the ED of the UHWI within 24 hours of their admission. The patients who were brought in dead or subsequently died after discharge from the ED after 24 hours were excluded. The records for those patients who received autopsies were further reviewed, and the following information extracted: age, gender, time of admission, time of death and clinical cause of death. A research number was assigned to each case to maintain the patients' privacy and confidentiality. The clinical cause of death was defined as that listed by the clinician on the patient's death card. For the purpose of this study, if more than one diagnoses was listed on the card, the diagnosis deemed most likely to have caused the death of the patient was selected. The corresponding post-mortem reports from the Department of Pathology were examined and the cause of death established at autopsy was documented. The diagnoses were coded according to the International Statistical Classification of Diseases, $10^{\text {th }}$ revision (ICD-10).

The clinical cause of death diagnoses were classified as being either concordant (similar) or discrepant (dissimilar) with respect to the pathologic diagnosis, using a modified Underwood classification $(5,6)$, as follows: 
Category I:

- major discrepancy

- missed principal diagnosis definitely affecting clinical outcome

Category II:

- major discrepancy

- missed principal diagnosis possibly affecting clinical outcome

Category III:

- minor discrepancy

- missed secondary diagnosis, either symptomatic but not treated, or likely to have affected prognosis

Category IV:

- minor discrepancy

- missed secondary diagnosis that could not have been made clinically

Category V:

- concordant diagnosis

Category VI:

- over-diagnosis, whether principal or secondary

The frequencies of the diagnostic discrepancies were analysed with respect to disease category, gender and age. Ethical approval for this study was granted by the University Hospital of the West Indies/The University of the West Indies/Faculty of Medical Sciences, Mona, Ethics Committee.

\section{RESULTS}

For the study period, 180 patients died in the ED within 24 hours of their admission and 68 of these patients received autopsies, yielding an autopsy rate of $37.8 \%$. Death certificates were issued by clinicians for the remaining 112 patients. The patients who received an autopsy ranged in age from 11-92 years (mean 54.9; median 51.5 years), with a male-to-female ratio of $1.4: 1$ (Fig. 1).

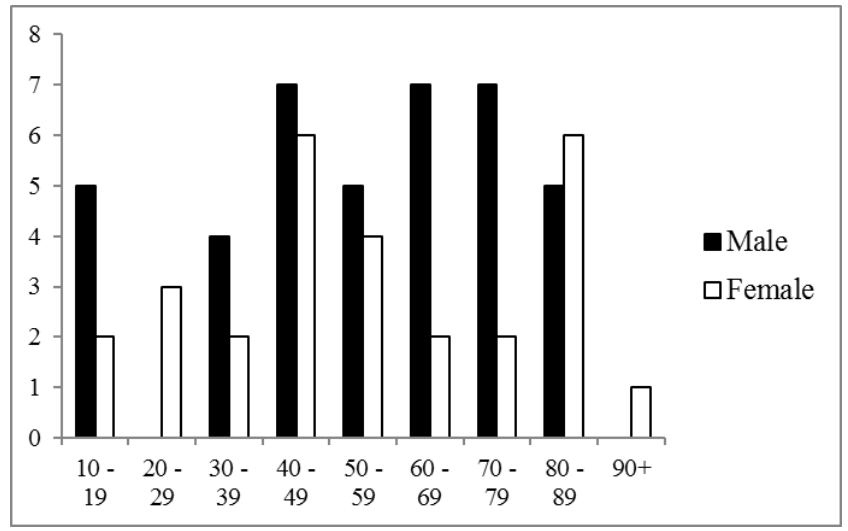

Fig. 1: Age and gender distribution of patients receiving autopsy $(n=68)$.
The causes of death established at autopsy were distributed among eleven ICD-10 categories, as shown in Table 1; the commonest category was circulatory disorders.

Table 1: Causes of death at autopsy, by ICD-10 category

\begin{tabular}{lcc}
\hline ICD Category & Number & $\mathbf{\%}$ \\
\hline Circulatory & 39 & 57.4 \\
Injury & 9 & 13.2 \\
Digestive & 4 & 5.9 \\
Respiratory & 4 & 5.9 \\
Neoplasms & 4 & 5.9 \\
Genitourinary & 2 & 2.9 \\
Infections & 2 & 2.9 \\
Blood and blood-forming organs & 1 & 1.5 \\
Nervous & 1 & 1.5 \\
Musculoskeletal and connective tissue & 1 & 1.5 \\
Unknown & 1 & 1.5 \\
\hline TOTAL & $\mathbf{6 8}$ & $\mathbf{1 0 0 . 0}$ \\
\hline
\end{tabular}

ICD: International Statistical Classification of Diseases

Deaths due to injuries were the second commonest cause of death overall; the majority $(55.6 \%)$ were penetrating injuries resulting from interpersonal violence. Road traffic accidents, electrocution and blunt trauma due to assault accounted for the remaining cases. A further breakdown of the circulatory disorders is detailed in Table 2; cardiovascular diseases were more common than cerebrovascular diseases.

Table 2: Causes of death, circulatory category

\begin{tabular}{lcc}
\hline Cause of death & Number & \% \\
\hline Cardiovascular & 27 & 69.2 \\
Ischaemic heart disease* & 10 & \\
Aortic dissection & 5 & \\
Pulmonary thromboembolism & 4 & \\
Hypertensive heart disease & 3 & \\
Cardiac failure & 2 & \\
Abdominal aortic aneurysm, ruptured & 1 & \\
Acute myocarditis & 1 & \\
Complete heart block & 1 & \\
Cerebrovascular & 12 & 30.8 \\
Subarachnoid haemorrhage & 5 & \\
Intracerebral haemorrhage & 3 & \\
Cerebellar haemorrhage & 1 & \\
Subdural haemorrhage & 1 & \\
Cerebral infarction & 1 & \\
Cerebrovascular accident, unspecified & 1 & \\
\hline TOTAL & $\mathbf{3 9}$ & $\mathbf{1 0 0}$ \\
\hline
\end{tabular}

*Five cases each of acute myocardial infarction and critical coronary artery stenosis 
Of the 68 cases, there were 25 (36.8\%) discrepancies between the clinical and autopsy causes of death diagnoses, accounted for by 22 patients. The discrepancies were represented only by Categories I and VI, with three patients exhibiting both a major missed diagnosis and an overdiagnosis. The majority (76\%) of the discrepancies belonged to Category I, including patients with both Categories I and VI discrepancies. Table 3 shows the clinical and autopsy causes of death in the discrepant cases; the majority of autopsy causes of death in Category I were represented by circulatory disorders.
Figure 2 shows the distribution of Category I discrepancies by age group and depicts increasing frequency of these discrepancies with increasing age, with the majority $(57.9 \%)$ occurring in patients aged 50 years and older. The majority (57.9\%) of Category I discrepancies were seen in the females.

\section{DISCUSSION}

The autopsy rate of $37.8 \%$ documented in this study is comparable with that of $43.2 \%$ reported in a similar ED in Glasgow (7). Kendall et al (8) reported a higher rate

Table 3: Clinical versus autopsy causes of death in (A) Category I discordant cases,

(B) Category VI discordant cases and (C) Categories I and VI discordant cases

\begin{tabular}{|c|c|}
\hline Clinical cause of death & Autopsy cause of death \\
\hline \multicolumn{2}{|l|}{ A: Category I discordant cases } \\
\hline \multicolumn{2}{|l|}{ Circulatory } \\
\hline Myocardial infarction & Aortic dissection \\
\hline Myocardial infarction & Aortic dissection \\
\hline Myocardial infarction & Abdominal aortic aneurysm, ruptured \\
\hline Myocardial infarction & Hypertensive heart disease with $\mathrm{CCF}^{*}$ \\
\hline Cerebrovascular accident & Hypertensive heart disease with $\mathrm{CCF}^{*}$ \\
\hline Cerebrovascular accident & Critical coronary artery stenosis \\
\hline Pulmonary thromboembolism & Critical coronary artery stenosis \\
\hline Pulmonary thromboembolism & Metastatic malignant spindle cell tumour \\
\hline Cardiopulmonary arrest & Emphysema \\
\hline \multicolumn{2}{|l|}{ Infections } \\
\hline Sepsis, ARDS $\dagger$ & Hypertensive heart disease with $\mathrm{CCF}^{*}$ \\
\hline Sepsis & CCF in patient with sickle cell anaemia \\
\hline Sepsis, pneumonia & Pulmonary thromboembolism \\
\hline Septic shock & Acute renal failure \\
\hline \multicolumn{2}{|l|}{ Gastrointestinal } \\
\hline Upper gastrointestinal haemorrhage & Bacterial meningitis \\
\hline Upper gastrointestinal haemorrhage & Brain tumour (parietal lobe) \\
\hline \multicolumn{2}{|l|}{ Genitourinary } \\
\hline Chronic renal failure & Septicaemia; infected dialysis fistula site \\
\hline \multicolumn{2}{|l|}{ B: Category VI discordant cases } \\
\hline \multicolumn{2}{|l|}{ Circulatory } \\
\hline Myocardial infarction & $\begin{array}{l}\text { Complete heart block; no infarction or } \\
\text { significant coronary artery disease }\end{array}$ \\
\hline Ischaemic heart disease & No anatomical cause of death \\
\hline $\begin{array}{l}\text { Pulmonary thromboembolism/Pulmonary } \\
\text { oedema }\end{array}$ & Aspiration pneumonitis \\
\hline \multicolumn{2}{|l|}{ C: Categories I and VI discordant cases } \\
\hline Pulmonary thromboembolism & Left ventricular failure due to chronic RHD \\
\hline Pulmonary thromboembolism & Mixed connective tissue disease \\
\hline Cerebrovascular accident & Aspiration pneumonitis \\
\hline
\end{tabular}

CCF: congestive cardiac failure; ARDS: acute respiratory distress syndrome; RHD: rheumatic heart disease 


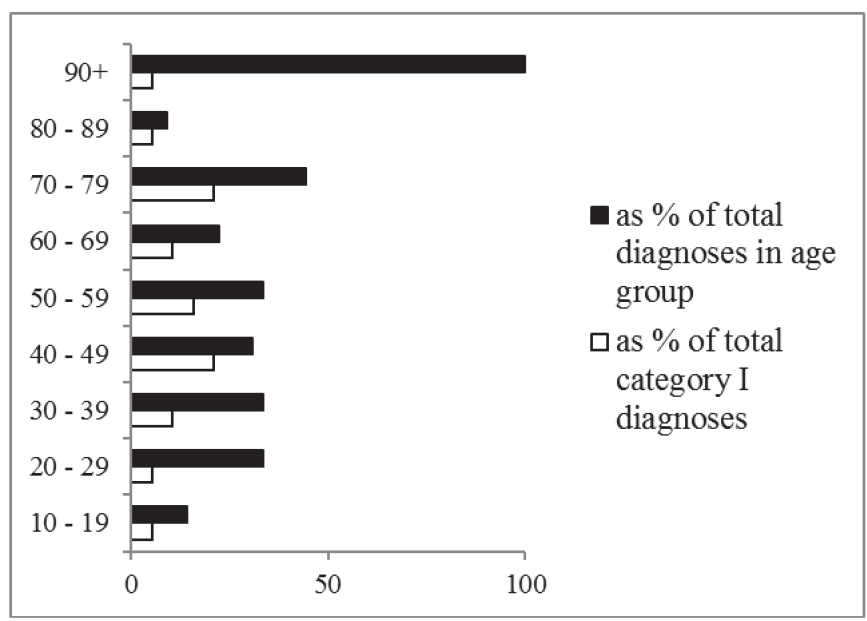

Fig. 2: Category I discordances by age group.

$(55 \%)$ in their 1988 study, and this may be a reflection of the generally higher autopsy rates that existed universally at the time and which have shown subsequent decline (4, 9 ). The mean age of the patients who received autopsies (54.9 years) is lower than that reported for the overall cohort dying in the emergency room [62.3 years] (10). The commonest age group represented at autopsy was the 4049-year age group, which contrasts with the older age groups that constituted the majority of the overall deaths (10) and may reflect an increased disposition to requesting autopsy in younger patients.

Circulatory disorders accounted for the commonest causes of death documented by autopsy and this is in keeping with global mortality data (11), as well as the data from similar ED autopsy studies $(7,8)$. The commonest circulatory cause of death was ischaemic heart disease $(25.6 \%)$, and this is again, in keeping with the global mortality data which showed ischaemic heart disease to be the leading cause of death, worldwide (11). Combined causes of intracranial haemorrhage contributed a proportion similar to that of ischaemic heart disease, to deaths in the circulatory category. The prominence of cerebrovascular accident as a cause of sudden natural death in our population has been previously documented (12). In keeping with a similar ED study by Kendall et al (8), injury was the second commonest cause of death category in this study. However, whereas in Kendall's study (8) most injuries were the result of road traffic accidents, in ours, penetrating injuries due to interpersonal violence were the commonest form (55.6\%). This is consistent with the profile of injuries generally seen at our institution (13).

Our overall discrepancy rate $(36.8 \%)$ between the clinical and autopsy cause of death diagnoses was simi- lar to that reported by Mushtaq and Ritchie [39.7\%] (7). Other papers have reported discrepancy rates for clinical and autopsy diagnoses, not limited to the cause of death diagnoses, ranging from $28 \%$ to $60 \%(2,14-18)$. A previous study from this institution, documented an overall discrepancy rate of $48.4 \%$ and a rate in the ED of $66.4 \%$ (5); these higher rates most likely reflect the inclusion of all the diagnoses for each patient, versus cause of death diagnoses only in the current study.

The discrepancies were represented solely by Categories I (76\%) and VI (24\%), with three patients having both. This distribution is not surprising, given the focus of this paper on the cause of death diagnoses, where minor diagnostic discrepancies (Categories III and IV) would not be expected to factor.

Category I discordant diagnoses were predominantly circulatory. In terms of the diseases represented, aortic disease was relatively more common than reported in other series, but similar to the data reported by Tavora et al (19), for patients dying within 24 hours of their admission. In other series, ischaemic heart disease and pulmonary thromboembolism were the commonest $(7,20)$. All our cases, of missed aortic disease, were clinically diagnosed as acute myocardial infarction; this highlights the importance of including aortic disease in the differential diagnoses of patients presenting with acute chest/abdominal symptoms. Cardiac failure complicating a range of chronic heart diseases was also a common cause of discrepancy, with the corresponding clinical diagnoses falling within both circulatory and non-circulatory disease categories. The prominence of cardiac failure as a missed diagnosis may relate to the infrequent subtlety of its symptoms and signs, particularly in patients with co-morbidities. This is exemplified by our patient with rheumatic heart disease, who, in addition to having a missed diagnosis of left ventricular failure, had an overdiagnosis of pulmonary thromboembolism.

In the current study, the proportion of total diagnoses that were Category I discrepancies increased with age. Additionally, the majority of Category I discrepancies were seen in patients aged 50 years and older. This trend of increased proportion of discrepancies with increasing age has also been documented in other studies $(4,21-23)$, including the previous study from our institution (5). It is possible that vague symptomatology and, often, multiple co-morbidities, in older age groups, may complicate the interpretations of clinical findings and hamper the elucidation of principal diagnoses. The current data has shown that although the majority of deaths in the ED occurred in older patients, autopsies were more 
likely to be requested in younger patients. As it has been shown that death certificates issued in the absence of autopsy data are frequently inaccurate $(24,25)$, and the clinical determinations of the principal diagnoses in older patients are often difficult, it would seem vital to increase the autopsy rate in older age groups.

Although the majority of patients who received autopsy were males, the majority of Category I discrepancies were seen in females. A greater discrepancy rate in females than in males has also been described in other studies $(15,22)$, but this finding has not been universally documented $(1,23)$ and its relevance is therefore uncertain.

Circulatory diseases also comprised the majority of Category VI discrepant diagnoses, notably ischaemic heart disease and pulmonary thromboembolism. These diseases were also the commonest overdiagnoses in the study by Mushtaq et al (7) and in the previous discrepancy study from our hospital (5).

It is worth highlighting that the patients in this study died within 24 hours of their presentation to the ED, some within a few minutes or hours, and this relatively short-time period of clinical contact is challenging in terms of performing and interpreting relevant investigations.

In conclusion, the autopsy rate and distribution of the cause of death diagnoses documented in our ED are comparable to those reported in similar studies. Our data suggest that including aortic disease in the differential diagnoses of patients with acute chest or abdominal pain, and meticulous clinical examination to detect subtle signs of cardiac failure may help in improving the accuracy of clinical diagnoses and patient management in the ED. The rate of the discrepant cause of death diagnoses was also similar to that reported in previous studies. Of significance is that the majority of discrepancies in our study occurred in older patients and they were less likely than younger patients to receive autopsies. Given the documented unreliability of death certificate data provided in the absence of autopsy, and the problems inherent in elucidating accurate principal clinical diagnoses in older patients, particularly in an emergency care setting, these all point to the need to improve the autopsy rate in the ED, with particular consideration for the older age groups.

\section{REFERENCES}

1. Goldman L, Sayson R, Robbins S, Cohn LH, Bettman M, Weisberg $\mathrm{M}$ et al. The value of the necropsy in three medical eras. $\mathrm{N}$ Engl J Med 1983; 308: 1000-5.

2. Ermenc B. Discrepancies between clinical and post-mortem diagnoses of causes of death. Med Sci Law 1999; 39: 287-92.
3. Kirch W, Schafii C. Misdiagnosis at a university hospital in 4 medical eras. Medicine (Baltimore) 1996; 75: 29-40.

4. Wittschieber D, Klauschen F, Kimmritz AC, von Winterfield M, Kamphues C, Scholman HJ et al. Who is at risk for diagnostic discrepancies? Comparison of pre- and postmortal diagnoses in 1800 patients of 3 medical decades in East and West Berlin. PLoS ONE; 2012; 7: e37460.

5. Gibson TN, Shirley SE, Escoffery CT, Reid M. Discrepancies between clinical and post-mortem diagnoses in Jamaica: A study from the University Hospital of the West Indies. J Clin Pathol 2004; 57: 980-5.

6. Underwood JCE. Autopsies and clinical audit. In: Burton JL, Rutty GN, eds. The hospital autopsy, $2^{\text {nd }}$ ed. London: Arnold; 2001: 170-7.

7. Mushtaq F, Ritchie D. Do we know what people die of in the emergency department? Emerg Med J 2005; 22: 718-21.

8. Kendall IG, Wynn SM, Quinton DN. A study of patients referred from A\&E for coroners post-mortem. Arch Emerg Med 1993; 10: 86-90.

9. Escoffery CT, Shirley SE. Necropsy rates at the University Hospital of the West Indies, 1968-1997. West Indian Med J 2000; 49: $164-8$.

10. Williams EW, Williams-Johnson J, Rhudd A. Causes of death within the first 24 hours of admission to an urban emergency department. West Indian Med J 2012; 61 (Suppl 6): 48.

11. World Health Organization. The top 10 causes of death. Fact sheet No. 310 [Internet]. World Health Organization; 2014 [cited February 2015]. Available from: http://www.who.int/mediacentre/ factsheets/fs $310 / \mathrm{en} /$.

12. Escoffery CT, Shirley SE. Causes of sudden natural death in Jamaica: A medicolegal (Coroner's) autopsy study from the University Hospital of the West Indies. Forensic Sci Int 2002; 129: 116-21.

13. Crandon I, Carpenter R, McDonald A. Admissions for trauma at the University Hospital of the West Indies. A prospective study. West Indian Med J 1994; 43: 117-20.

14. Stevanovic G, Tucakovic G, Dotlic R. Correlation of clinical diagnoses with necropsy findings: a retrospective study of 2,145 consecutive necropsies. Hum Pathol 1986; 17: 1225-30.

15. Battle RM, Pathak D, Humble CG, Key CR, Vanatta PR, Hill RB et al. Factors influencing discrepancies between premortem and postmortem diagnoses. JAMA 1987; 258: 339-44.

16. Carvalho FM, Widmer MR, Cruz M. Clinical diagnosis versus necropsy. Bull Pan Am Health Organ 1991; 25: 41-6.

17. Sarode VR, Datta BN, Banerjee AK, Banerjee CK, Joshi K, Bhusnurmath B. Autopsy findings and clinical diagnoses: a review of 1,000 cases. Hum Pathol 1993; 24: 194-8.

18. Olle-Goig JE, Canela-Soler J. The value of the necropsy in a rural hospital of Haiti. Trop Doct 1993; 23: 52-4.

19. Tavora F, Crowder CD, Sun CC, Burke AP. Discrepancies between clinical and autopsy diagnoses. A comparison of university, community, and private autopsy practices. Am J Clin Pathol 2008; 129: 102-9.

20. Aalten CM, Samson MM, Jansen PAF. Diagnostic errors; the need to have autopsies. Neth J Med 2006; 64: 186-.90.

21. Saad R, Yamada AT, Pereira da Rosa FH, Gutieriez P, Mansur A. Comparison between clinical and autopsy diagnoses in a cardiology hospital. Heart 2007; 93: 1414-9.

22. Kotovicz F, Mauad T, Saldiva PHN. Clinico-pathological discrepancies in a general university hospital in São Paulo, Brazil. Clinics (Sao Paulo) 2008; 63: 561-8. 
23. Spiliopoulou C, Papadodima S, Kotakidis N, Koutselinis A Clinical diagnoses and autopsy findings. A retrospective analysis of 252 cases in Greece. Arch Pathol Lab Med 2005; 129: 210-4.

24. Quigley M, Burton J. Evidence for cause of death in patients dying in an accident and emergency department. Emerg Med J 2003; 20: 349-51.
25. Kircher T, Nelson J. Burdo H. The autopsy as a measure of accuracy of the death certificate. N Engl J Med 1985; 313: 12639. 